\title{
EL RECOLECTOR DE COLILLAS DE CIGARRILLO EN LA HISTORIA DE LA LITERATURA, LA PRENSA Y LA CULTURA VISUAL
}

\author{
Dorde Cuvardic García
}

\begin{abstract}
RESUMEN
Entre las llamadas industrias de la calle se encuentra el trapero, figura que ha acaparado la atención de diversos investigadores. Entre los diversos tipos de trapero se encuentra el recolector de colillas de cigarro. Las representaciones culturales sobre este tipo social todavía no se han analizado. El objetivo de este artículo es, precisamente, sacar del olvido a esta figura. Se encuentra en multitud de representaciones literarias, periodísticas y visuales de los siglos XIX y XX. Objeto de estetización, aparece en el costumbrismo español (Estébanez Calderón), la prensa de bulevar francesa y española, la litografía (Daumier), la escultura, la novela española del siglo XX (Cela) y el cine. En este último caso, se ha rastreado la presencia del recolector de colillas de cigarrillo en dos películas de Chaplin (El chico, Luces de la ciudad), en el documental Berlín, sinfonía de una gran ciudad, de Walter Ruttmann, y en $M$, una ciudad busca un asesino, de Fritz Lang.

Palabras clave: Recolector de colillas de cigarrillo, trapero, industria de la calle, literatura, prensa, cine.
\end{abstract}

\begin{abstract}
Among the various people making their living off of the street, the junkman has monopolized the attention of a number of researchers. Among the various types of junkmen is the collector of cigarette butts. Cultural representations of this social type have not as yet been analyzed. The aim of this article is to reclaim this figure from oblivion. He is represented in a multitude of literary, journalistic and visual representations of the 19th and 20th centuries. Subject to aestheticization, he appears in Spanish costumbrism (Estébanez Calderón), French boulevard press and Spanish lithography (Daumier), sculpture, Spanish novels of the twentieth century (Cela) and film. In the latter case, this article has tracked the presence of the cigarette butt collector in two films of Charlie Chaplin (The Guy, Lights of the City), in the documentary Berlin: Symphony of a Great City, Walter Ruttmann, and the film $M$, a city looks for a murderer, by Fritz Lang.

Key words: Collector of cigarette butts, junkman, street industry, literature, press, cinema.
\end{abstract}

Dr. Dorde Cuvardic García. Profesor de la Escuela de Filología, Lingüística y Literatura. Universidad de Costa Rica. Correo electrónico: dcuvardic@yahoo.es

Recepción: 05- 10- 2011

Aceptación: 08- 11- 2011 


\section{Introducción}

El trapero es un conocido tipo de vagabundo urbano. Muchas veces, en todo caso, no se toma en cuenta que, a su vez, existen diversas modalidades de este tipo social: una de ellas es el recolector de colillas de cigarrillo. 'Oficio menudo' donde los haya, muy pocas personas, en la actualidad, sospecharían de su existencia. De hecho, en las numerosas investigaciones realizadas sobre el trapero, incluyendo la única monografía existente sobre esta última figura, no se menciona ni investiga al recolector de colillas. Y, sin embargo, no solamente ha existido (nuestros abuelos llegaron a conocerlo), sino que además ha obtenido carta de representación artística en diversas prácticas significantes.

El apogeo del trapero (también del recolector de colillas) está motivado por las condiciones productivas de la industrialización en el siglo XIX, como señala Benjamin: "Los traperos aparecieron en mayor número en las ciudades desde que los nuevos procedimientos industriales dieron a los desperdicios cierto valor. Trabajaban para intermediarios y representaban una especie de industria casera que estaba en la calle" (1997: 31).

Una definición de recolector de colillas es la siguiente: Es aquella persona que, ya sea como desempeño laboral regular o como actividad anecdótica, recolecta colillas con el propósito de fabricar, con el tabaco reunido, nuevos cigarrillos y puros. Todo oficio desarrolla una terminología especializada sobre la materia prima que trabaja. Así, este tipo social discrimina entre diversos tipos de colillas. En este sentido, en Francia existe toda una tipología de colillas, como explica Kline: "si es demasiado pequeña para ser fumada, se llama orphelin, mientras que una buena colilla tiene por nombre boni (del latín aliquid boni, 'algo bueno')" (1993: 193).

Podemos plantear las siguientes preguntas de investigación: ¿existen suficientes documentos donde se identifique al recolector de colillas como un tipo específico de trapero?, ¿es amplia la representación del recolector de colillas en la historia de la cultura occidental?, ¿qué periodo cubre el auge de sus representaciones culturales?, ¿qué actividades ejecuta?, ¿se realiza crítica social en estos textos?, ¿se explican los determinantes sociales de su aparición?

Ya que no es un tipo social suficientemente estudiado desde la antropología, discursos como las representaciones literarias, cinematográficas y artísticas se convierten en un invaluable documento histórico para analizarlo ${ }^{1}$. Estas fuentes constituyen un recurso invaluable para conocer su comportamiento, sus instrumentos, la actitud que la sociedad asume frente a su marginalidad...

Metodológicamente, el analista debe proceder, asimismo, como un recolector de 'colillas' descriptivas. De la misma manera que el recolector de colillas recupera lo que los fumadores desechan, el investigador dedicado a analizar este tipo social debe prestar atención a aquellas descripciones que, por lo general, en textos literarios y audiovisuales, no acaparan el interés del crítico literario o del historiador del arte, dedicado al análisis de grandes estructuras narrativas. Por lo general, no es protagonista: forma parte de los personajes secundarios que ‘amueblan' el mundo posible de la ficción.

\section{El recolector de colillas de cigarrillo en la escritura costumbrista española}

Este tipo social se puede reconocer a partir del siglo XIX. El costumbrismo español se ocupó del recolector de colillas en el artículo "Fisiología y chistes del cigarro", de las Escenas andaluzas, de Serafín Estébanez Calderón. Es un artículo del tópico sobre los modos de vivir 
que no dan de vivir, en línea con el artículo de Larra del mismo nombre. El personaje 'Puntillas', sinónimo de colillas, detalla sus inicios como recolector: "me supe ganar yo por mis propios merecimientos el renombre de Puntillas, por la singular afición que desde tamañito saqué de buscar, allegar y hacer caudal de todos los cabos, restos, trozos, pedazos y pintas de cigarro que por doquiera hallaba" (Estébanez Calderón 1985: 342). Describe, asimismo, los espacios por los que transita, en lo que define como filosofía peripatética: "paseando, discurriendo y divagando por entre los trebejos de los cafés y tertulias, dando agradable cebo así a esta nueva clase de caza y montería" (1985: 342). 'Puntillas' caza (es decir, busca) colillas. Seguidamente, describe el proceso de elaborar nuevos cigarrillos, una vez que cuenta

\footnotetext{
con pañuelos colmados de estos tesoros. Todos ellos puestos al pique ya de sendas tijeras o tajantes cuchillas, triturados debidamente, acribados con limpieza y pasando por la hábil manipulación de mi buen ingenio y arte, ofrecían agradable materia para los inteligentes, que se embebecían de placer saboreándola en los pulcros, lindos y encanutados pitillos en que yo me la sabía embutir y acomodar. (342)
}

El recolector desmenuza las colillas, amontona el tabaco resultante y, después de un proceso de limpieza y con papel de fumar, procede a elaborar nuevos cigarrillos, que hace pasar y vende como nuevos, en lo que se puede considerar como acto de picaresca.

Por su parte, las colecciones de tipos sociales costumbristas en España no incorporan a este tipo social, ni siquiera en los artículos sobre sectores sociales desclasados. Los españoles pintados por sí mismos, por ejemplo, sólo menciona a la cigarrera en la esfera del tabaco ${ }^{2}$.

\section{El recolector de colillas de cigarrillo en la cultura escrita francesa (siglo XIX)}

En la segunda mitad del siglo XIX abundan los textos franceses, procedentes de diferentes géneros, que se ocupan del recolector de colillas. En cualquier cosa, predomina este tipo social en la literatura de bulevar, que busca describir el espacio público con una actitud amable. El capítulo XIII "Las colillas de cigarrillos" ("Les bouts de cigares"), de La capucha del trapero (La hotte du chifonier) (1885), de Louis Paulian, se dedica en primer lugar a describir el trabajo cotidiano del recolector de colillas. El recolector trabaja sobre todo en las horas que presencian cafés llenos de clientes 3 :

\footnotetext{
El recolector de colillas de cigarros es un tipo parisino. Es, aún así, un especialista que no trabaja más que a ciertas horas y que no trabaja sino en su barrio. Cuando los cafés se llenan, toma su sombrero y su bastón, llega al bulevar y comienza su paseo diario. He ahí que sigue la acera; sus ojos están fijos en el suelo y, cuando percibe una colilla de cigarro o cigarrillo, le pica con la pequeña ganzúa con la que termina su bastón y lo hace desaparecer en su bolsillo. (174-175)
}

No trabaja dentro del café, sino en la acera de este establecimiento: muchos clientes tiran colillas al entrar o al salir. Destaca la descripción de bastón del recolector. Mientras que el del trapero tradicional cuenta con una punta metálica, con la que pica los desechos, el del recolector cuenta con una ganzúa.

Paulian procede a estructurar una visión idealizada del recolector. El enunciador declara que obtiene sustanciosas ganancias de su oficio, cuando en realidad su actividad apenas le da para sobrevivir"

Cuando lo observas, te apiadas de su suerte, y el pequeño empleado del ministerio que le ve reunir los cigarrillos que arroja después de haberlo fumado hasta el fondo, se dice a sí mismo: “¡He aquí alguien que es desgraciado!". Error, error grave. El recolector de colillas de cigarro no cambiaría su posición frente a ninguna sub-prefectura de Francia. Si conoce bien su oficio, debe vivir cómodamente. (175) 
Precisamente para demostrar a los lectores que esta actividad es lucrativa, el narrador decide acompañar en su trabajo a algunos recolectores de colillas. No asume este último papel (es decir, no asume el papel antropológico del típico participante observador que de vez en cuando adopta el distanciamiento reflexivo del analista), sino que es un simple acompañante ${ }^{5}$. Es, simplemente, un observador ('j'ai constaté de visu', declara) ${ }^{6}$ :

\footnotetext{
He querido darme cuenta de los beneficios que puede obtener un recolector de colillas y, cuando he trapeado con los traperos, he realizado diversas excursiones con los recolectores de colillas de cigarrillos. He constatado directamente que uno de estos especialistas que opera en la región de la estación de San Lázaro llegó fácilmente a reunir, de cuatro a siete horas diarias, alrededor de 3 francos de tabaco. La gran sala de los pasos perdidos de la estación de San Lázaro, a la hora de la barrida general, proporciona alrededor de 6 francos de tabaco, mientras que una sala de café-concierto otorga de 6 a 7 francos. Delante de la Madelaine, los días en los que hay una gran boda o un gran funeral, el recolector de colillas encuentra su pieza de cuarenta sous y, si es hábil, sabe encontrar una segunda pieza de cuarenta céntimos bajo los mercados de la ópera entre el segundo y el tercer acto. (175)
}

Seguidamente, Paulian detalla el procedimiento de confeccionar cigarros a partir de las colillas. Al describir la actividad de procesar las colillas recolectadas para preparar nuevos cigarrillos, se percibe de nuevo el encuadre económico del enunciador ${ }^{7}$ :

\footnotetext{
El recolector de colillas de cigarros, cuando su cosecha ha terminado, empieza su parte; siguiendo su gusto, meterá en su pipa, sea colillas de Londres, ya sea caporal ordinario; posteriormente, preparará el resto para la venta. Se trata de adornar la mercancía y de hacer cortes. Los cigarrillos son desmenuzados y el tabaco es secado al sol. Las colillas de los cigarros, después de ser igualmente secadas, son picadas en pedacitos. Todo es mezclado, reunido y metido en pequeños paquetes que se venden a diez céntimos. (175-176)
}

Otro texto que nos ofrece detalladamente la cotidianeidad del recolector de colillas es el capítulo tercero de El camino del crimen (Le chemin du crimen) (1889), de Hugues Le Roux, titulado "Los recolectores de colillas" ("Les ramasseux de mégots"). Al igual que en La capucha del trapero, en este texto de Le Roux también se mencionan los lugares más favorables para la recolección de colillas, como son "el patio de la Halle aux Blés, la bolsa del Louvre, los cafés de los bulevares, los jardines públicos, en verano, y los músicos militares” $(123)^{8}$. Es decir, las prácticas de la sociabilidad pública burguesa y pequeño-burguesa (cafés, conciertos al aire libre), ocasiones donde se consumen cigarrillos y puros, proporcionan la mayor cantidad de colillas para el recolector. Su horario de trabajo se detalla más en el texto de Le Roux que en el de Paulian: "A las dos horas de la mañana, después del cierre de las cervecerías, se inician su giras. Se trata de peinar la acera antes del paso de los barrenderos. Al mediodía, un segundo recorrido. A las nueve y media, tercera gira, hacia las puertas de los restaurantes y las salas de espectáculos" (122-123) ${ }^{9}$. Uno de los oficios que el recolector de colillas considera como competencia es el de barrendero: reúne en una masa informe, sin separar, todo tipo de desperdicios. A diferencia del texto de Paulian, donde se declaran pingües beneficios de la recolección de colillas, Le Roux considera que las ganancias son escasas. Un industrial de la calle acucioso "puede esperar reunir céntimo a céntimo cincuenta gramos por gira. Un buen día se logran hasta cincuenta céntimos" $(123)^{10}$.

Pierre Véron menciona brevemente al recolector de colillas en "El conductor de ómnibus" ("Le cocher' d'omnibus"), capítulo doce de su obra Los objetivos de un paseante de bulevar (Les Propos d'un boulevardier) (1888), al destacar que los escritores de la prensa popular ['fabricants de feuilletons'] ya se han ocupado de 'poetizar' ['poétiser'], en el sentido de estetizar, a todos los tipos sociales habidos y por haber, entre ellos a los recolectores de cigarros: 
"Tenía la intención de poetizar al recolector de colillas de cigarrillo, hijo fracasado de una ilustre familia, el alumbrador de farolas" (Verón 1888: 135) ${ }^{11}$. Se trata de una alegoría ingeniosa: el recolector de colillas como ‘hijo fracasado' del alumbrador de farolas. Mientras este último ilumina los grandes puros metafóricos de la ciudad (los faroles), el primero se encarga de recoger los puros y cigarrillos literales que ya han sido apagados, es decir, consumidos.

También aparece en la canción popular francesa decimonónica. Charles Aubert cuenta con Le ramasseur de bouts de cigares (1880: 5-8), y Françoise Vergeron con una canción del mismo nombre, publicada en el volumen Les industries de la Rue (1869: 106-109).

Como puede verse por las últimas fuentes que han sido mencionadas y comentadas, el recolector de colillas es un tipo social de moda en la cultura popular francesa de la segunda mitad del siglo XIX.

Ya en la cultura española, pero en directa respuesta a la francesa, en la escena III del Cuadro Primero de Carmela, Parodia-Lírica de la Ópera Carmen, de Salvador María Granés, con música de Tomás Reig, estrenada el 21 de enero de 1891 en el Teatro Principal de Barcelona, aparece un coro de colilleras ${ }^{12}$. Las llamadas segundas dicen "Yo recojo colillas", las primeras prosiguen "Y yo las lío", mientras que las terceras terminan con "Y yo las vendo". En este caso, la 'cigarrera' se ha degradado a 'colillera'.

\section{El recolector de colillas de cigarrillo en la prensa española (siglo XIX)}

La prensa periódica, y en particular la española, ofrece una fuente importante para obtener información sobre el desempeño y la inserción de este tipo social en la estructura económica urbana. Así, la crónica Cartas Parisienses, de 1875, firmada bajo el pseudónimo Pico de la Mirandola, publicada en el número XLI de La Ilustración Española y Americana, se dedica a los tipos sociales marginales (el enunciador declara seguir el modelo del clásico artículo de Larra Modos de vivir que no dan de vivir). Dedica un párrafo al coleccionista de colillas de cigarros:

\footnotetext{
¿Y los coleccionistas de colillas de cigarros? ¡Qué tipo tan parisiense! Dícese que pasan de ciento los que viven de esta industria, explotando los desperdicios de 300.000 cigarros que cada día se consumen en París, y me han enseñado uno, días pasados, sobre el bulevar, que arrastra coche centralizando estos despojos temidos de los recaudadores del estanco. (De la Mirandola 1875: 287)
}

El enunciador lo considera como un tipo social típico de París. Se asume una mirada curiosa sobre sujetos cuya excepcionalidad es el 'ingenio' que utilizan para sobrevivir. Por otra parte, menciona a otro de los grandes enemigos del recolector de colillas: nos referimos a los estancos que expenden tabaco.

La Ilustración Española y Americana nos ofrece otra importante contribución sobre la pertenencia de tipo social a las prácticas económicas callejeras de París. De nuevo Pico de la Mirandola, en la crónica París íntimo, describe el sistema laboral que gira alrededor de la recuperación de la materia prima de las colillas:

\footnotetext{
Uno de los más generosos protectores de estas debutantas [de las revistas de los teatros de esta ciudad], es por cierto, un industrial especialísimo, jefe de un ramo de comercio singular, y a quien atribuye la fama tan pingües utilidades, que le llaman el Rotschild de las puntas de cigarro.

El comercio de estos desperdicios, que cosechan con avidez febril y simiesca habilidad centenares de colilleros dispersados por todos los ámbitos de París, se concentraba hasta estos días en la calle des Lavandières, donde funcionaba una verdadera Bolsa o Mercado Central de tales residuos, que, después de purificados con diversas manipulaciones, se embalan en sacos y se venden á la gruesa, llegando las transacciones a sumas muy respetables.
} 


\begin{abstract}
Esta semana precisamente la Bolsa de las colillas se ha trasladado a la orilla izquierda del Sena, a una callejuela vecina del boulevard Saint Germain por demolición del callejón en que antes funcionaba. Este ha desaparecido con motivo de las mejoras urbanas que se están llevando a cabo a propósito del próximo centenario de la Revolución. (De la Mirandola 1889: 15-18)
\end{abstract}

El corresponsal llama a esta actividad industria, como también sucede en los textos franceses. Y, como tal, las cifras manejadas, en términos económicos, podían llegar a ser muy altas. Es lo que piensa Louis Poulain, como ya vimos. Según Becerro de Bengoa, corresponsal de La Ilustración española y Americana en Londres, el Ministro de Hacienda británico, Michael Hicks Beach, llegó a afirmar en 1896 en una ocasión que "el valor de las colillas de puros y cigarros de papel que los fumadores tiran, llega a un millón de libras esterlinas" (1896: 279).

No son las únicas menciones del recolector de colillas en La Ilustración Española y Americana. Otra fuente nos indica que se trata de un 'oficio' callejero presente en otras grandes capitales. Al hablar de los higos, Julián Manuel de Sabando, en el artículo Un elemento más, comenta que "constituye la granjería de los desheredados y de muchachos parecidos a los que en Madrid se dedican a recoger colillas y puntas de cigarros por las calles" (1894: 194). En este último caso, la práctica de la recolección de colillas se sitúa en Madrid y ya no en París.

\title{
5. El recolector de colillas en la novela y el cuento español (siglos XIX y XX)
}

No será extraño encontrar al recolector de colillas en las escenas callejeras de los escritores naturalistas, en su propósito de describir los espacios moralmente 'degradados' que la sociedad industrial ha provocado en la periferia de las ciudades. En la Sección II del capítulo sexto de La desheredada, de Galdós, cuando unos niños juegan en un terreno baldío, menciona el narrador:

\footnotetext{
Antes de llegar a las altas posiciones comerciales tenían que pasar por humillante aprendizaje y penoso noviciado. ¡Recoger colillas! Ved aquí un empleo bastante pingüe. Pero tal comercio tiene algo de trabajo, y exige recorrer ciertas calles, instalarse en las puertas de los cafés, consagrarse al negocio con cierta formalidad. Eran niños, necesitaban juego como el pez necesita agua, y así por las tardes se iban al río a recoger matacandiles. (2005: 99-100)
}

Como en el caso francés, se considera un 'oficio' lucrativo, aunque una futura investigación podría indagar si se trata de enunciados irónicos. Se considera un 'oficio’ de muchachos, como en la fuente madrileña mencionada al final del apartado anterior, procedente de Sabando. Exige, además, cierta sistematicidad: conocer la topografía de la ciudad y las horas de máxima asistencia a los espacios de la sociabilidad pública.

El cesante será un tipo proclive a recoger colillas de cigarro, ya no en términos profesionales, sino esporádicamente, por incapacidad económica para comprar cigarrillos en los estancos. El cesante don Cleto Meana, uno de los tantos tipos sociales que pueblan la segunda parte de El árbol de la ciencia, de Pío Baroja, acostumbra a realizar esta actividad sin ser observado por los transeúntes, en razón de la degradación social que implica recoger colillas del suelo:

\footnotetext{
Don Cleto paseaba por el Retiro y Recoletos; se sentaba en los bancos, entablaba conversación con la gente; si no le veía nadie, cogía algunas colillas y las guardaba, porque, como era un caballero, no le gustaba que le sorprendieran en ciertos trabajos menesteres. (Baroja 1997: 91)
}

En Torquemada en el Purgatorio, de Galdós, no se menciona el mendigo callejero que recolecta colillas, sino su comercio. El narrador expresa las valoraciones que la opinión pública 
madrileña lanza contra el personaje Cruz del Águila: “Que Cruz recogía las colillas de los que fumaban en su casa, para mandarlas al Rastro en un costal muy grande, así como juntaba también los mendrugos de pan, para venderlos a unos que hacían chocolate de dos reales y medio..." (la cursiva es añadida) (Pérez Galdós 1946: 76-77). Esta fuente indica que en Madrid, al igual que en París, existía cierto comercio que traficaba con el tabaco de las colillas.

Dos relatos de la cuarta serie de los Episodios Nacionales de Galdós mencionan la actividad del recolector de colillas. Uno de ellos es Los duendes de la camarilla. Cuando Domiciana le pregunta a Lucila si el Capitán fuma, esta última añade: “-Sí que fuma cuando tiene qué. Yo recojo todas las colillas que encuentro; se las pico muy bien picaditas..." (la cursiva es añadida) (Pérez Galdós 1944-1951: 1645). En este caso, Lucila no es colillera como oficio regular, sino como desempeño coyuntural. Es una actividad realizada para satisfacer una necesidad personal. Se recogen colillas para consumo privado, como también ocurre con don Cleto, de El árbol de la ciencia.

El segundo caso procede de Narváez. El General Narváez llega a decir en cierto momento: "Tampoco serviría en la Corte por nada de este mundo. Primero sería sereno del barrio, salvaguardia, rebuscador de colillas" (la cursiva es añadida) (Pérez Galdós 1944-1951: 1588). En este caso se demuestra que 'recolectar colillas de cigarrillo' es una actividad identificada y tipificada por los ciudadanos en la España decimonónica. ¿Cómo queda valorada dentro de la escala de los oficios por una persona perteneciente a un alto estamento como es el General Narváez? Se considera entre los oficios bajos (equiparado al de sereno o al de salvaguardia).

En el cuento Jactancia, de Emilia Pardo Bazán, aparece un golfillo que sobrevive mediante la recolección de colillas, entre otras actividades. El narrador, que no menciona su nombre, con el objetivo de escarmentar a unos amigos que se jactan de cometer maldades como pose decadentista, termina por prepararles una broma. Contrata a un muchacho y le sitúa en una habitación remodelada como cámara de tortura para hacer creer a sus amigos que le somete a torturas diarias. Del muchacho menciona que "tres días antes, aún recogía colillas y pedía limosna” (Pardo Bazán 1947: 1629). Este cuento, así como las fuentes anteriores, nos demuestran que el recolector de colillas es un tipo social familiar en la España decimonónica.

\section{El recolector de colillas en el realismo social de Camilo José Cela}

A mediados del siglo XX, época de penuria económica, en Viaje a la Alcarria (1948), de Camilo José Cela, se encuentra un excepcional documento que nos demuestra la exclusión social que sufre este tipo social marginal. El recolector de colillas de cigarrillo es objeto de escarnio:

\footnotetext{
Por el andén pasa un mendigo barbudo recogiendo colillas. Se llama León y lleva unas alpargatas color azul celeste. Un hombre le dice: 'Ven, León, que te tengo mucho cariño. ¿Quieres un pitillo?”. Cuando León se le acerca, le da una bofetada que suena como un trallazo. Todos se ríen, mientras León, que no ha dicho ni una palabra y que lleva los ojos llenos de lágrimas, como un niño, se marcha silencioso, mirando para el suelo, agachándose de trecho en trecho para recoger una colilla. Desde el final del andén, León vuelve la cabeza. En sus ojos no hay ni cariño ni odio; parecen los ojos de un ciervo disecado, de un buey viejo y sin ilusión. Va sangrando por la nariz. (Cela 1969: 37-8)
}

Se trata de un mendigo fumador que recoge colillas con regularidad. Este personaje ya tiene asumida, desde hace tiempo, la violencia social ejercida sobre él por la sociedad.

La Colmena (1951), de Cela, nos ofrece diversas descripciones que nos indican la importancia que tienen las colillas de cigarrillos para los fumadores en tiempos de crisis económica, de post-guerra en este caso. El cerillero Padilla enuncia importantes reflexiones 
sobre la calidad que tiene el tabaco de las colillas, una vez extraída la materia prima: "Mire usted, el tabaco de las colillas siempre se nota; por más que lo laven siempre le queda un gusto un poco raro. Además, el tabaco de colillas huele a vinagre a cien leguas y aquí ya puede usted meter la nariz, no notará nada raro" (Cela 1971: 101). En tiempos de penuria, no sólo los mendigos recolectan cigarrillos. El bohemio Martín Marco, por ejemplo, utiliza un sobre "que ya no sirve para nada más que para llevar colillas, o clavos, o bicarbonato" (1971: 169) Más adelante, en una escena callejera, extrae una colilla en buen estado del sobre: "El sereno se aleja y Martín, a la luz de un farol, busca en su sobre otra colilla en buen uso" (1971: 179).

Martín Marco es un buen ejemplo de aquellas personas que asumen la recolección de colillas como actividad coyuntural, sin convertirla en oficio, por necesidad. Es una táctica emprendida por fumadores que, en periodos de penuria económica (como el fin de la Segunda Guerra Mundial, o la primera post-guerra en España), y en situación de dificultad económica personal, se ven precisadas a crear nuevos cigarrillos a partir de colillas. Julio, el narrador de Escenas de cine mudo (1994), de Julio Llamazares, relata su infancia en Olleros, transcurrida durante los años sesenta en España, y narra cómo iba al puente de La Salera, "para fumar los cigarros que le robaba a mi padre o fabricaba yo mismo con el tabaco de sus colillas" (1944: 55). En este último caso, es un adolescente que no puede comprar cigarrillos y los fabrica a partir de las colillas abandonadas por su padre.

\section{El recolector de colillas de cigarrillo en la cultura visual}

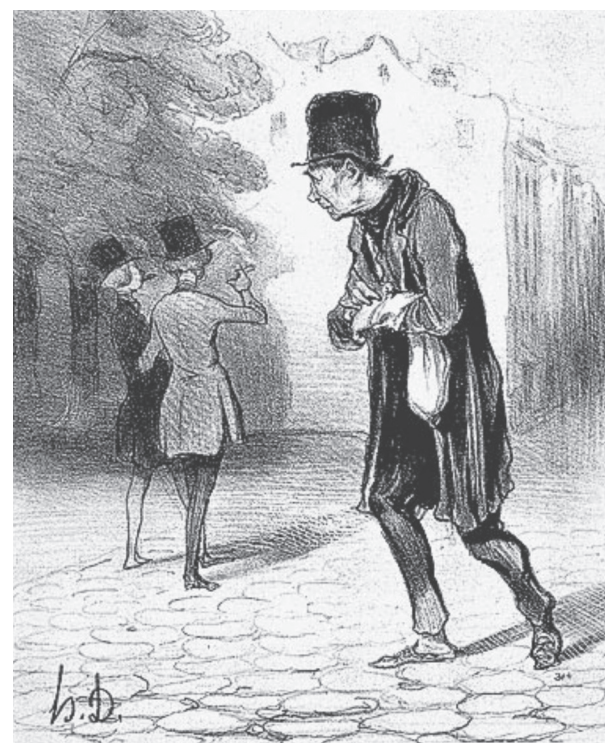

Figura 1. Honoré de Daumier, 1842.

"El recogedor de colillas de cigarros"

Placa 4. Serie: Bohemios de París.

Podemos identificar al recolector de colillas de cigarrillo en tres prácticas visuales: la caricatura, la fotografía y el cine. Iniciamos las representaciones visuales con Honoré Daumier y su litografía El recogedor de colillas de cigarrillo, publicada en el periódico Le Charivari, el 5 de diciembre de 1841, placa número 4 perteneciente a la serie Bohemios de París [Bohémiens 
de Paris]. Lleva una bolsita donde previsiblemente amontona las colillas que ha ido recogiendo durante el día, y observa con cierta expectativa a dos burgueses 'espigados' que fuman con placer. Espera el momento en que la pareja arroje las colillas al suelo para, seguidamente, recogerlas y depositarlas en la bolsa. Honoré Daumier también tiene una escultura en bronce titulada El vagabundo. El rodante o el recolector de colillas de cigarrillo (The Vagrant. Le rodeur ou le ramasseur de bouts de cigares), de 1832-1835.

Por su parte, a lo largo de la historia del cine han aparecido diversos recolectores de colillas de cigarrillo, sobre todo en los primeros cincuenta años de historia del séptimo arte.

En el cine documental surge el recolector de colillas en una escena callejera de Berlín, una sinfonía de la gran ciudad, de Walter Ruttmann (1927). Cuenta con una línea narrativa propia. Es un pequeño sintagma narrativo en un documental principalmente descriptivo. Un caballero tira al suelo una colilla de cigarrillo frente a un automóvil y un trapero la recoge (cuenta con el tradicional saco y bastón). Este último repite la operación dos veces más. La intención es mostrar que este trapero toma colillas del suelo con regularidad.
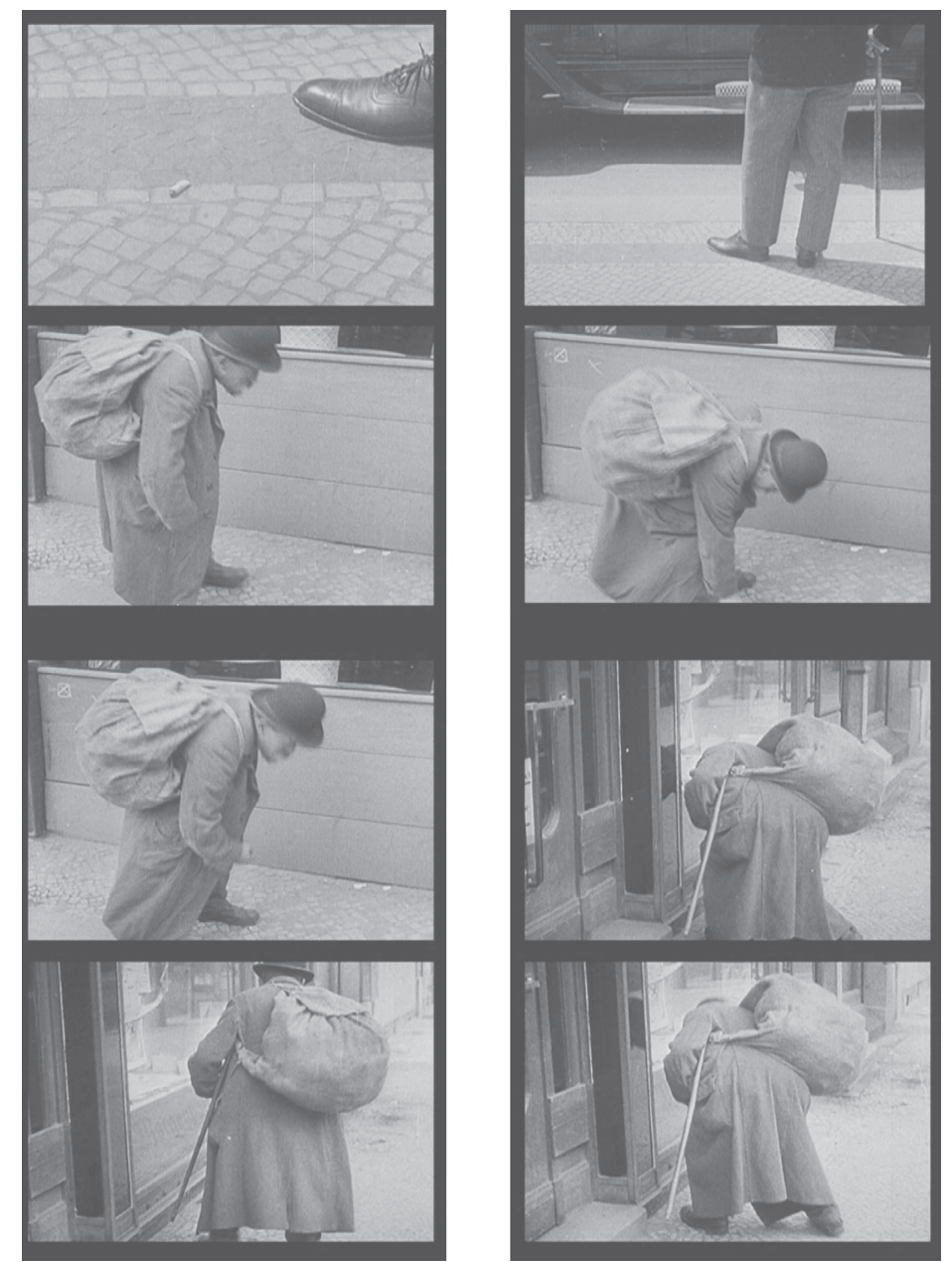

Figura 2. Berlin. Die Simphonie eine grosse Stadt.

Dir: Walter Ruttmann. 65 minutos, B/N, Edition Filmuseum. 
También podemos considerar como trapero el mendigo que, en una escena de $M$, Una ciudad busca un asesino (M, Eine Stadt sucht ein Mörder) (1931), de Fritz Lang, abre una caja de hojalata y ordena sobre una mesa diversos tipos de cigarrillos y puros que, previsiblemente, se ha preparado el mismo. Al final elige un puro y lo fuma.
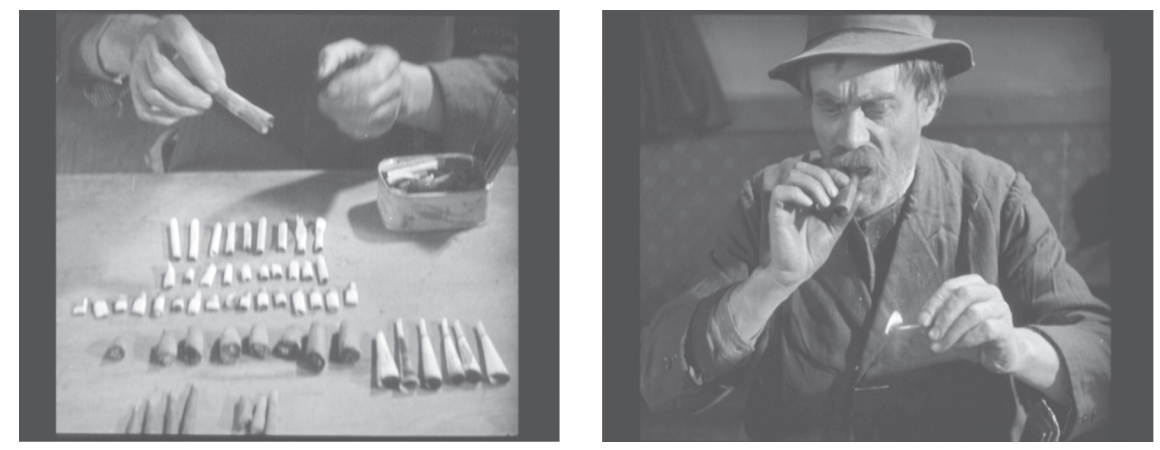

Figura 3. M, Una ciudad busca un asesino.

Dir: Fritz Lang. 87 minutos, B/N, Universum Film.

Son diversas las apariciones del recolector de colillas de cigarrillo en las películas de Charles Chaplin. Charlot es un trapero y, como tal, está acostumbrado a recolectar colillas. En El chico (The Kid) (1921), en la escena inicial, la primera acción que realiza Charlot, una vez que se acerca a la cámara, es sacar un cigarrillo de una caja de hojalata y encender un cerillo. Después de varios intentos, lo prende y se lo fuma. De nuevo inferimos que se ha fabricado tabaco a partir de la recogida de colillas y del papel para fumar que tiene guardado.
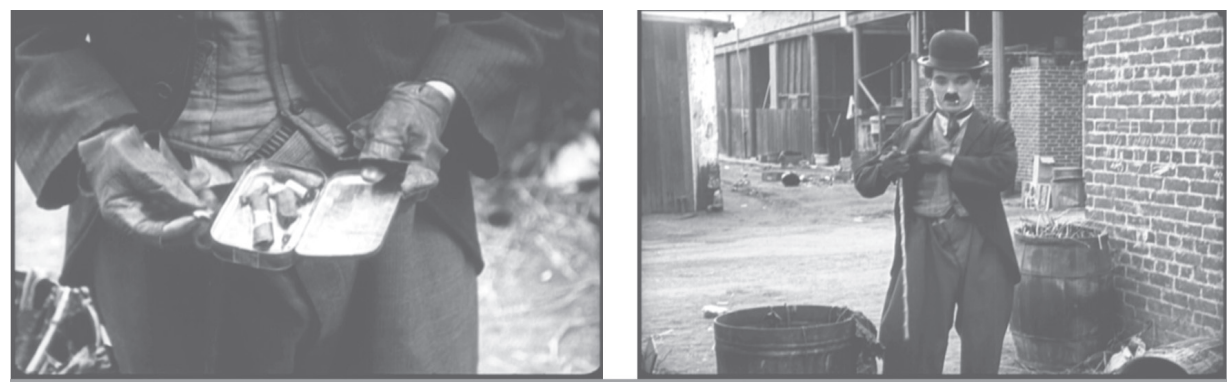

Figura 4. El chico. Dir: Charles Chaplin. 68 minutos, B/N, Triad Productions.

Otra importante aparición del acto de recoger colillas aparece en Luces de la ciudad, de 1931. Un millonario le presta su automóvil a Charlot, después de una noche de juerga. Cuando descubre una colilla, se baja rápidamente del automóvil, empuja a un mendigo para que no la atrape antes que él, la agarra y se la lleva. El mendigo se queda perplejo, al ver a un 'supuesto' millonario que acaba de pelearse con él por una 'simple' colilla.

El espantapájaros (Scarecrow) (1973), de Jerry Schatzberg, nos presenta a dos vagabundos, interpretados por Gene Hackman y Al Pacino. El primero de ellos fuma constantemente. Al inicio de la película recoge una colilla y habla sobre la calidad de la marca del cigarrillo de la que procede. En este caso no hablamos de un recolector de colillas por oficio, 
sino de un vagabundo fumador que, en lugar de comprar cigarrillos o tabaco, prefiere consumir las colillas que recoge del suelo.

Una comedia española, La tonta del bote (1970), de Juan de Orduña, representa a una recolectora de colillas de cigarrillo. En esta película, el personaje, Susana, recoge colillas y las guarda en un bote. A continuación se las entrega a un ciego, quien por cada siete puntas de cigarrillo consigue fabricar una nueva. Esta película es una adaptación de un sainete de Pilar Millán Astray estrenado en 1925.

\section{Conclusiones}

En este artículo hemos probado la existencia de una modalidad de trapero que no había sido identificada hasta ahora en las prácticas culturales occidentales. Históricamente, el recolector o simple recogedor de colillas aparece, tanto histórica como culturalmente, en épocas de penuria económica. Y, sobre todo, tiene su máxima expresión entre 1830 y 1930 , cuando el capitalismo estaba embarcado en la revolución industrial, antes del surgimiento del Estado del bienestar. Los excedentes de esta sociedad eran utilizados por los desclasados como actividad económica o como medio para ahorrarse la compra de tabaco nuevo.

Los textos culturales no ofrecen, por lo general, el proceso de preparación de nuevos cigarrillos a partir de colillas. Se ocupan, más bien, del proceso de recolección de colillas (los lugares donde se pueden obtener, los objetos donde se pueden guardar). El recolector considera al barrendero como su competidor directo, mientras que el estanquillero lo percibe como una competencia de su actividad legal de venta de cigarrillos y puros.

La literatura de bulevar francesa, la prensa española y los textos literarios costumbristas y realistas españoles del siglo XIX nos indican la existencia de este 'oficio', convertido en práctica social y económica. En el siglo XX, la literatura del realismo social (Cela) y el cine, en lugar de la recolección sistematizada de una actividad económica, tematizan la recogida de colillas por individuos que no cuentan con los medios suficientes para comprar puros o cajas de cigarrillos.

El recolector cuenta con una iconografía fija. Su principal instrumento es el bastón, adaptación del que utiliza el trapero, que ostenta una punta metálica en uno de sus extremos: cuenta con una pinza para recoger las colillas. Usa diversos medios para depositar y reunir el fruto de su trabajo. En la caricatura de Daumier emplea una bolsita; Marcos Martín utiliza un sobre en La colmena, de Cela; en El camino del crimen, de Hugues Le Roux, se menciona un pequeño saco; en $M$, Una ciudad busca a un asesino, de Fritz Lang, y en El chico, de Chaplin, una caja de hojalata.

El recolector de colillas de cigarrillo es un tipo social sujeto a procesos de estetización. Entendemos por estetizar describir a un tipo social (en la elaboración de su prosopografía -o descripción física- y su etopoya -o descripción psicológica-), sin que el enunciador se interese por analizar críticamente las condiciones sociales que han provocado su surgimiento, y sin indagar en su percepción de la sociedad. El recolector de colillas, en consecuencia, es objeto de contemplación estética. En particular, se le convierte en un personaje cómico y pintoresco (por ejemplo, se le caricaturiza). La exclusión social y el escarnio no son prácticas sociales que aparezcan regularmente en estas representaciones. La única excepción que hemos encontrado a este proceso de estetización, práctica por lo demás común en la representación de la Otredad, es Viaje a la Alcarria, de Cela. 


\section{Notas}

1. Es lo que ha hecho, por ejemplo, Peter Burke (2005) en Visto y no visto. Madrid: Cátedra.

2. VV. AA. 2002. Los españoles pintados por sí mismos. Madrid: Editorial Visor.

3. A continuación se ofrece el original en francés: "Le ramasseur de bouts de cigares es un type parisien. C'est encoré un spécialiste qui ne travaille qu'à certaines heures et ne fait que son quartier.-Au moment où les cafés se remplissent de monde, il prend son chapeau et sa canne, arrive sur le boulevard et commence sa promenade jounalière. Le voilà qui suit le trottoit; ses yeux son fixés à terre, et, dès qu'il aperçoit un bout de cigare ou cigarette, il le pique avec le petit crochet qui termine sa canne et le fait disparaître dans sa poche."

4. A continuación se ofrece el original en francés: "En l'apercevant, vous vous apitoyez sur son sort, et le petit employé de ministère qui lui voit ramasser la cigarette qui'il vient de jeter après l'avoir cependant fumée jusqu'au bout, se dit en lui-même: «En voilà un qui est bien malheureux!» Erreur, erreur profonde. Le ramasseur de bouts de cigares ne troquerait pas sa position contre la meilleure sous-préfecture de France. S'il connaît bien son métier, el doit en vivre et en vivre aisément".

5. Es típico de la escritura costumbrista, a escala internacional, que el enunciador acompañe al tipo social callejero mientras ejecuta su oficio. Es el caso, por ejemplo, de Mesonero Romanos, quien acompaña al sereno en el artículo Madrid a la luna, de las Escenas matritenses.

6. A continuación se ofrece el original en francés: "J'ai voulu me rendre compte des bénéfices que peut réaliser un ramasseur de bouts de cigares et, de même que j’avais chiffonné avec de chiffoniers, j'ai fait plusieurs excursions avec des ramasseur de bouts de cigares. J'ai constaté de visu qu'un de ces spécialistes que opère dans la región de la gare Saint-Lazare arrivait facilement à ramasser, de quatre à sept heures du soir, pour 3 francs de tabac. La grande salle des pas perdus de la gare Saint-Lazare, à l'heure du balayage general, donne pour près de 6 francs de tabac, unse salle de café-concert rapporte 6 a 7 francs. Devant la Madeleine, les jours où il y a un grand mariage ou «un gros mort», le ramasseur de bouts de cigars trouve sa pièce de quarante sous, et, lorsqu'il est habile, il sait trouver une seconde pièce de quarante sous sur les marches de l'Opera entre le second et le troisième acte." (en cursiva en el original).

7. A continuación se ofrece el original en francés: "Le rammasseur de bouts de cigares, quand sa récolte est terminée, commence par faire sa part; suivant son goût, il metra dans sa pipe, soit des bouts de londrès, soit du caporal ordinaire; puis il préparera le reste pour la vente. Il s'agit de parer la marchandise et de faire des coupages. Les cigarettes sont défaites et le tabac est séché au soleil. Les bouts de cigares, après avoir été également séchés, son hachés en petits morceaux. Le tout est mélangé ensemble et enfermé dans de petits cornets qui se vendent 10 centimes"

8. A continuación se ofrece el original en francés: "le cours de la Halle aux Blés, la bourse du Louvre, les cafés des boulevards, en été les jardins publics, et les musiques militaires".

9. A continuación se ofrece el original en francés "A deux heures du matin, après la fermeture des brasseries, ils commencent leurs tournées. Il s'agit de glaner le trottoir avant le passage des balayeurs. A midi, seconde course. A neuf heures troisième tournée, aux portes des restaurants et des salles de spectacle".

10. A continuación se ofrece el original en francés: "peut espérer récolter cent à cent cinquante grammes par tournée. Une bonne journée rapporte jusqu'à cinquante sous".

11. A continuación se ofrece el original en francés: "Ils avaient entrepis de poétiser le ramasseur de bouts de cigares, fils déchu d'une illustre famille, l'allumeur de réverbéres".

12. Salvador María Granés. Carmela. Parodia-Lírica de la Ópera Carmen (Música de Tomás Reig). Biblioteca Virtual Miguel de Cervantes Saavedra. 16. http://cervantesvirtual.com Consulta: 15 de noviembre del 2010.

\section{Bibliografía}

Aubert, Charles. 1880. Le ramasseur de bouts d'cigares. Paris: Barbré.

Baroja, Pío. 1997. El árbol de la ciencia. Madrid: Alianza. 
Becerro de Bengoa, Ricardo. 1896. "Por ambos mundos". La Ilustración Española y Americana. 40 (17): 279.

Benjamin, Walter. 1997. "El París del Segundo Imperio en Baudelaire”. En: Poesía y capitalismo. Iluminaciones II. Madrid: Taurus.

Burke, Peter. 2005. Visto y no visto. Madrid: Cátedra.

Cela, Camilo José. 1969. Viaje a la Alcarria. Barcelona: Destino.

1971. La colmena. Madrid: Alfaguara.

Estébanez Calderón, Serafín. 1985. Escenas andaluzas. Madrid: Cátedra.

García Ruíz, Víctor y Gregorio Torres Nebrera. 2003. Historia y antología del teatro español de posguerra. Volumen I: 1940-1945. Madrid: Fundamentos.

Klein, Richard. 1993. Cigarettes are sublime. Durham y Londres: Duke University Press.

Granés, Salvador María. Carmela. Parodia-Lírica de la Ópera Carmen (Música de Tomás Reig). Biblioteca Virtual Miguel de Cervantes Saavedra. http://cervantesvirtual.com.

Les membres du caveau. 1869. Les industries de la rue. Paris: Ch. Grou, Libraire-Editeur de Musique et Chanson.

Le Roux, Hugues. 1889. Le chemin du crimen. Paris. Victor-Havard.

Llamazares, Julio. 1994. Escenas de cine mudo. Barcelona: Seix Barral.

Mirandola, Pico de la. 8.1.1875. “Cartas parisienses”. La Ilustración Española y Americana. 19 (41): 287.

8.1.1889. "París íntimo”. La Ilustración Española y Americana. 33 (1): 15-18.

Pardo Bazán, Emilia. 1947. “Jactancia”. Obras completas. Tomo I. Novelas. Cuentos. Madrid: Aguilar.

Paulian, Louis. 1885. La hotte du chiffonier. Paris: Librairie Hachette et Cie.

Pérez Galdós, Benito. 1944-1951. "Los duendes de la camarilla”. En: Obras completas II. Madrid: Aguilar.

1944-1951. “Narváez”. En: Obras completas II. Madrid: Aguilar.

1946. Torquemada en el purgatorio. Buenos Aires: Losada.

2005. La desheredada. Madrid: Alianza.

Sabando, Julián Manuel de. 30.09.1894. “Un elemento más”. La Ilustración Española y Americana. 38 (36): 194.

VV. AA. 2002. Los españoles pintados por sí mismos. Madrid: Visor.

Véron, Pierre. 1888. Les propos d'un boulevardier. Paris: Dentu.

\section{Filmoteca}

Chaplin, Charles. 1921. The Kid. Estados Unidos: Warner Home Video, B/N. 68 min. 1931. City Lights. Estados Unidos: United Artist, B/N. 87 min. 
Lang, Fritz. M. Eine Stadt sucht einen Mörder. Alemania: Vereinigte Star-Film GmbH, B/N. 87 min.

Orduña, Juan de. 1970. La tonta del bote. España: José Frade P.C., Color. 105 min.

Ruttmann, Walter. 1965. Berlin. Die Simphonie eine grosse Stadt. Alemania: Bundesarchiv Berlin. ZDF/ARTE Mainz, B/N. 65 min.

\section{Ilustración}

Honoré de Daumier. 1842. "Le ramasseur de bouts de cigares". Placa 4 de la Serie Bohemios de París. Litografía. 